\title{
The role of misinformation in the information practices of Iraqi asylum seekers in Finland
}

\author{
Hilda Ruokolainen \\ Åbo Akademi University \\ hilda.ruokolainen@abo.fi \\ https://orcid.org/0000-0003-2521-4390
}

Keywords: misinformation; asylum seekers; information practices

When arriving in a new country, asylum seekers often receive too little or too much information. Accurate information is important for being socially included but it is often available fragmentarily through different channels, sources and social networks. Furthermore, there have been multiple changes in the Finnish asylum policies in the past few years. Asylum seekers have varying information needs, which are connected with, for example, their new situation in Finland and family and friends in their home country. Different social networks, especially peer communities, are important information sources. However, the quality, i.e. the informativeness and trustworthiness, of the networks varies. Their old information practices may not be effective in the new setting. This complex information situation exposes asylum seekers to misinformation.

The aim of my $\mathrm{PhD}$ project is to study the role of misinformation in the information practices of Iraqi asylum seekers during their asylum-seeking process in Finland. It is studied what asylum seekers perceive as misinformation, what kind of misinformation they encounter and how they use it. Furthermore, their social networks and cognitive authorities are studied in order to understand the different characteristics in their information practices that are connected with the presence of misinformation.

Studies on information practices have not in general focused on misinformation or even considered it as a part of information practices. Yet, misinformation is present, especially in the vulnerable situation of asylum seekers, and This article is licensed under the terms of the CC BY-NC-SA 4.0 -license 
it affects their lives, well-being and social inclusion. Earlier studies show that misinformation that asylum seekers encounter can be, for example, outdated information, official information, rumours or distorted information. They receive it through gatekeepers and other information mediators. Misinformation can give them false hope or unrealistic expectations in their situation. However, as misinformation has not been the focus of studies on asylum seekers, more empirical data is needed on types of misinformation and information practices related to misinformation. Second problematic aspect is that it is not always easy to say what misinformation is, as it is situational and the interpretation of it is bound to norms and other social and cultural factors.

The concepts of misinformation, information practices, social networks, cognitive authority and social inclusion form the theoretical framework of the study. Misinformation is inaccurate, uncertain, vague or ambiguous information that is false for the receiver in a certain moment in a given context (Karlova \& Lee, 2011). Whether something is interpreted as accurate information, misinformation or disinformation (deliberately deceptive information) is, however, situational and influenced by social and cultural factors, values and norms. With the concepts of normative and disnormative information it can be further understood that not all information is either true or false but generally accepted or disregarded according to the dominant attitudes (Haasio, 2015). Understanding the complexity of misinformation is vital when studying marginalized groups, such as asylum seekers, who may not share the same understanding of what is accurate information.

Information practices are socially and culturally established ways to identify information needs, seek information, evaluate, share and use it (Savolainen, 2008). The social process of learning into the new information environment and understanding how to deal with information in the new setting are emphasized in the concept of information practices (Lloyd, Kennan, Thompson, \& Qayyum, 2013). Social networks contain resources, such as information. Quality networks are important information sources for asylum seekers. However, networks can also be sources of misinformation, which decreases trust towards the whole network. Cognitive authorities (Wilson, 1983) influence individuals' and groups' thoughts and what information is trusted. Recognizing authorities is a learning process, which asylum seekers are forced to start in a new context. The concept helps to understand what misinformation is accepted and trusted and why.

Social inclusion refers to the possibility to fully participate in the society and influence one's own life. For this, physical and mental well-being and social support and access are needed. The concept helps to understand how information and misinformation affect the lives and well-being of asylum seekers. Social- 
ly excluded do not necessarily have access to mainstream information sources, which makes them more excluded, and this again prevents them from accessing official information (Caidi \& Allard, 2005). When accurate information is not available, asylum seekers turn to alternative sources that can disseminate misinformation. Social inclusion is a somewhat challenging concept in the interstitial position of asylum seekers but, nevertheless, their social inclusion is important for their own well-being and the surrounding society.

The topic is important for the field of Library and Information Science, where the awareness of misinformation as a part of information practices or behaviour is still developing. The study has also societal importance by creating knowledge about the information situation of asylum seekers in Finland. Understanding the presence of misinformation in the lives of asylum seekers helps service providers and other actors give accurate information that is in an understandable, usable and culturally meaningful form for the asylum seekers. Receiving accurate information is important for their social inclusion.

\section{References}

Caidi, N., \& Allard, D. (2005). Social inclusion of newcomers to Canada: An information problem? Library \& Information Science Research, 27(3), 302-324. https://doi.org/10.1016/ j.lisr.2005.04.003

Haasio, A. (2015). Disnormatiivinen ja normatiivinen informaatio. Informaatiotutkimus, 34(4). https://journal.fi/inf/article/view/53512

Karlova, N. A., \& Lee, J. H. (2011). Notes from the underground city of disinformation: A conceptual investigation. Proceedings of the American Society for Information Science and Technology, 48(1), 1-9. https://doi.org/10.1002/meet.2011.14504801133

Lloyd, A., Kennan, M. A., Thompson, K. M., \& Qayyum, A. (2013). Connecting with new information landscapes: Information literacy practices of refugees. Journal of Documentation, 69(1), 121-144. https://doi.org/10.1108/00220411311295351

Savolainen, R. (2008). Everyday information practices : A social phenomenological perspective. Lanham: Scarecrow Press.

Wilson, P. (1983). Second-hand knowledge: An inquiry into cognitive authority. Westport: Greenwood Press. 